\title{
Testing of blister propagation and peeling of orthotropic bituminous waterproofing membranes
}

\author{
Biruk W. Hailesilassie $\cdot$ Sivotha Hean • \\ Manfred N. Partl
}

Received: 9 April 2013/Accepted: 14 November 2013/Published online: 21 November 2013

(C) RILEM 2013

\begin{abstract}
Bridge decks are commonly subjected to harsh environmental conditions that often lead to serious corrosion problems, which are triggered by blisters under the hot mix asphalt bridge deck pavement with waterproofing membranes. These blisters are secretly evolving during weather exposure until often being detected too late. Formation of blisters under the waterproofing membrane is caused by a complex mechanism governed by bottom-up pressure and loss of adhesion. This paper primarily intends to adopt the analytical blister propagation energy approach for waterproofing membranes and compare it with adhesive fracture energy from standard peeling test methods, already described in the literature. Three different types of polymer modified bitumen membranes (PBM) were used for this purpose. The investigation includes a comparison between uniaxial
\end{abstract}

B. W. Hailesilassie $(\bowtie) \cdot$ M. N. Partl

Infrastructure Engineering, Division of Highway and Railway Engineering, School of Architecture and the Built Environment, Royal Institute of Technology (KTH), 10044 Stockholm, Sweden

e-mail: biruk.hailesilassie@abe.kth.se

M. N. Partl

e-mail: manfred.partl@empa.ch

S. Hean - M. N. Partl

Road Engineering/Sealing Components, Swiss Federal

Laboratories for Material Science and Technology

(EMPA), Ueberlandstrasse 129, 8600 Duebendorf,

Switzerland

e-mail: sivotha.hean@empa.ch and biaxial testing conditions for determining the modulus of elasticity of the membranes. Moreover, the influence of the displacement rate and temperature on the adhesive fracture energy in peeling tests is investigated. It was found that the biaxial modulus of PBM in the longitudinal and transversal direction is comparable with the uniaxial tension testing results in the main directions. In addition, it was observed that the ratio of longitudinal and transversal modulus of elasticity was similar. The energy calculated from tests with elliptical blister propagation showed a comparable value to the standard peeling fracture energy for similar types of PBM.

Keywords PBM waterproofing membrane .

Orthotropic material · Biaxial test · Peeling test ·

Elliptical blister growth - Digital image

correlation

\section{Background of the blister test}

It is known that blistering effects can be found on bridge decks, multistory car parks, tunnels or pedestrian areas (e.g. sidewalks). When hot mastic is applied to concrete, blisters may occur either between the dense asphalt layers and the polymer modified bitumen waterproofing membrane (PBM) [1, 2], or between the waterproofing membrane and the structural concrete of the bridge deck [3]. Pressure produced by air and water vapor under the pavement 
is the main reason for blister formation [4]. In particular, it can be caused by the expansion of hot humid air in the concrete after torching of the membrane with open gas flame. This paper focuses on blistering of orthotropic PBM, which are frequently used as flexible sheets for waterproofing on concrete bridge decks to prevent water infiltration from the pavement to the concrete surface. The application process and the material properties determine functionality of PBM and the strength of adhesion to the concrete, both having a significant impact on the life span of concrete bridges.

Generally, PBM are composed of one or two reinforcing carrier layers that are coated on both sides with polymer-bitumen sealing material. The polymer-bitumen sealing material is a mixture of polymer modified bitumen, mineral fillers and polymers. Polymers are almost exclusively modified either with an elastomer, i.e. styrene-butadiene-styrene copolymer (SBS), or with a plastomer, i.e. atactic polypropylene (APP). A typical SBS-PBM contains 10-15 mass\% SBS-copolymer and 30-40 mass\% filler whereas an APP-PBM contains about 25-30 mass\% APP-polymer and 10-30 mass\% filler [3]. The nominal standard thickness of a PBM for waterproofing of bridge decks is $5 \mathrm{~mm}$. Since PBM are normally attached to the concrete surface by heat welding with a flame or hot air, properties and functionality of the PBM can be affected by high welding temperatures which can reach up to $400{ }^{\circ} \mathrm{C}$ if hot air is used and $600-800{ }^{\circ} \mathrm{C}$ if a gas torch is chosen [5]. Moreover, these high temperatures during the welding process can affect the strength of the concrete, e.g. by producing tension in the upper surface followed by cracking of the concrete. The adhesion between the concrete and the PBM can be improved by using low-viscosity epoxy resin as bonding agent after sandblasting or water jetting the concrete plate, etc. [6].

Insufficient adhesion and cohesion of the bituminous layer in the membrane and lack of strength of the concrete are the main causes for losing adhesive bond between concrete surface and PBM. Several adhesion tests are proposed and standardized, including pull-off tests [7], peeling and shear tests [8] and others. However, these tests are generally not acknowledged to capture the risk of adhesive blister formation in a reliable and realistic way [2] specially when it comes to orthotropic material behavior of the PBM under multi axial state of stress.
If the right representation is used, for instance true stress-strain relationship in case of large deformation, very similar material behavior can be found up to the second yielding point whether uniaxial tension test or biaxial extension test is used for elastic material [9]. The fracture toughness property $G_{\mathrm{A}}$, is a 'geometric independent' material property that characterizes the energy to break the interfacial bonding forces and the energy dissipated locally ahead of the peeling front in the plastic or viscoelastic zone at crack tip [10, 11]. The energy term needs to account for the stored energy in the peeling arm, the energy dissipated during tensile deformation of the peeling arm and the energy dissipated due to bending of the peeling arm [10, 12, 13]. This approach will be used in this paper for comparison with blister propagation energy [14]. Another common way of determining the fracture energy is through numerical modeling by using the cohesive zone crack propagation model via generalized 'Griffith' energy criteria, which works by limiting the maximum value of the stress in the damage zone ahead of the crack and is often used because of its physical significance $[12,15,16]$.

The blister test allows characterizing the adhesive propagation of blisters under 3D testing conditions in a pressure controlled situation which is more realistic than a deformation controlled setup. The blister test behavior can be modeled as crack propagation along the interface between the welded PBM sealant and the substrate, considering the relationship between the applied pressure and blister deflection [17]. From this relationship it is possible to determine the energy dissipated during debonding of the PBM.

\section{Objective of the study}

The primary objective of the study was to determine the analytical blister propagation energy and compare it with a standard peeling test method, as described in Swiss standards, and determine the adhesive fracture energy from literature [10, 12, 13]. Three different types of PBM were used for this investigation. The investigation includes the comparison between the uniaxial and biaxial test for determining the modulus of elasticity of the membranes. Influence of the displacement rate and temperature on adhesive fracture energy is also investigated for the peeling test. The other objective is to compare a new model that 
Table 1 Different layers of the polymer modified bitumen waterproofing membranes

\begin{tabular}{|c|c|c|c|c|c|}
\hline PBMllayer & a & $\mathrm{b}$ & $\mathrm{c}$ & $\mathrm{d}$ & $\mathrm{e}$ \\
\hline SBS-1(EP5 MA) & Talcum/sand & $\begin{array}{l}\text { Bitumen, SBS } \\
\text { polymers and filler }\end{array}$ & Polyester & $\begin{array}{l}\text { Bitumen, SBS } \\
\text { polymers and filler }\end{array}$ & PE-film \\
\hline SBS-2 (EP5 MA, WF) & Talcum/sand & $\begin{array}{l}\text { Bitumen, SBS } \\
\text { polymers and filler }\end{array}$ & Polyester & $\begin{array}{l}\text { Bitumen, SBS } \\
\text { polymers and filler }\end{array}$ & Sand \\
\hline APP (PPV5 MA, WF) & Talcum/sand & $\begin{array}{l}\text { Bitumen, APP } \\
\text { polymers and filler }\end{array}$ & $\begin{array}{c}\text { Polyester and } \\
\text { glass fabric }\end{array}$ & $\begin{array}{l}\text { Bitumen, APP } \\
\text { polymers and filler }\end{array}$ & PE-film \\
\hline
\end{tabular}

$M A$ hot mastic asphalt resistant, $W F$ root resistant, EP5 and PPPV5 are condensed material designations according to Swiss standards SIA 281, $P E$ polyethylene

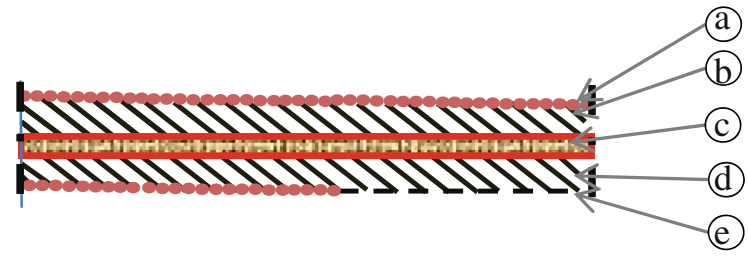

Fig. 1 Typical schema of the composition of polymer modified bitumen membranes $a$ top surfacing, $b$ top polymer-bitumen layer with mineral filler, $c$ carrier, $d$ bottom polymer-bitumen layer with mineral filler and $e$ bottom surfacing

allows determining the corresponding adhesive blister propagation energy [14] with the fracture energy equations for peeling as proposed in literature. Finally, this helps to understand the blister crack propagation of PBM on the top of the concrete surface and it's relation to the peeling test. It also helps to distinguish the adhesive properties of different types of membranes and their resistance to blister formation without conducting the time consuming and complicated pressurized blister propagation tests with digital image correlation techniques.

\section{Experimental method}

\subsection{Material and methodology}

The material used in the investigation includes three PBM with different components. Details of the membrane components are indicated in Table 1 based on the multilayer composition of waterproofing membranes as depicted schematically in Fig. 1.

In order to investigate the influence of temperature and loading rate on the fracture energy, SBS-1 waterproofing membrane was chosen and tested using uniaxial tension test at 23,40 and $55{ }^{\circ} \mathrm{C}$ in combination with 50,75 and $100 \mathrm{~mm} / \mathrm{min}$ displacement rate in the longitudinal direction. The uniaxial test performed for SBS- 1 at $23{ }^{\circ} \mathrm{C}$ and $50 \mathrm{~mm} / \mathrm{min}$ displacement rate is compared with biaxial test to check if the two testing conditions give similar stress-strain curves and moduli of elasticity. Three specimens each were tested in a uniaxial and biaxial experiment. After this, the uniaxial test is performed for SBS-1, SBS-2 and APP waterproofing membranes at $23{ }^{\circ} \mathrm{C}$ and $50 \mathrm{~mm} / \mathrm{min}$ displacement rate in the longitudinal and transversal direction to determine the modulus of elasticity in the respective direction. In addition to this, peeling test is performed for SBS-1 waterproofing membrane at 23, 40 and $55{ }^{\circ} \mathrm{C}$ in combination with 50,75 and $100 \mathrm{~mm} /$ min displacement rate in order to understand the influence of the temperature and the displacement rate on the peeling fracture energy. Peeling test is done in the longitudinal direction at $23{ }^{\circ} \mathrm{C}$ for SBS-1, SBS-2 and APP water proofing membranes to determine the peeling fracture energy. Blister test is performed on SBS-1, SBS-2 and APP waterproofing membranes at $23{ }^{\circ} \mathrm{C}$ by applying a controlled pressure. The pressure was set to $0.2 \mathrm{MPa}$ during the testing period. Blister height and crack propagation in the longitudinal and transversal direction is measured using 3D image correlation system. Finally the blister propagation energy is compared with the fracture energy from peeling tests. A detailed description of the different tests is given below.

\subsection{Biaxial tension test}

In order to create a test for meaningful measuring mechanical material properties, mechanical characteristics and possible failure mechanisms of the material as well as geometrical design of the specimens must be taken into account. Cruciform specimens can be used to 


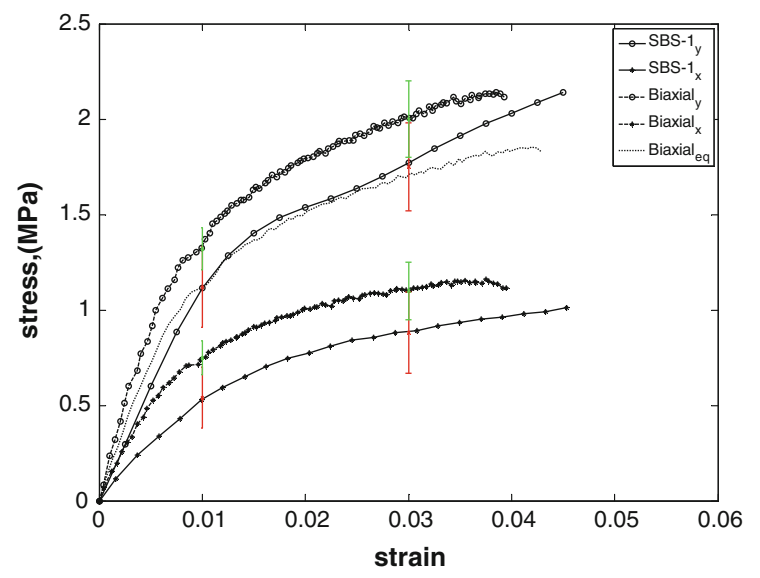

Fig. 2 Typical measured stress-strain curve at $23{ }^{\circ} \mathrm{C}$ from biaxial ( $y$ longitudinal, $x$ transversal) and uniaxial tension test

determine biaxial tension strength. This requires maximization of the region of the uniform biaxial strain, minimization of the shear strains in the biaxial loaded test zone as well as minimization of the strain concentration outside the test zone to create specimen failure within the biaxial loaded test zone [18]. Details of validating the biaxial test using a finite element (FE) model were presented by Hailesilassie and Partl [14]. A cruciform shaped PBM specimen was used with a total size of $1,000 \times 1,000 \mathrm{~mm}$ and a central part of $200 \mathrm{~mm}$ width. Slits were cut in each arm of the specimen to allocate a tensile deformation in the center of the specimen. Displacement at a rate of $40 \mathrm{~mm} / \mathrm{min}$ was applied. Strains in longitudinal and transversal direction in the center of the cruciform specimen were measured with two needle extensometers attached to the center of the specimen. The maximum engineering strain measured was $3.9 \%$. All the experiments were performed with a 1:1 loading ratio at room temperature of $23^{\circ} \mathrm{C}$.

The cruciform specimen was modeled using a linear elastic FE model to determine the stress causing the strain measured in the center of the specimen [14]. Due to the non-uniform stress distribution in the cruciform sample, a correction factor must be used [19]. For FE modeling of the cruciform specimen, Poisson's ratios $v_{x y}$ and $v_{y x}$ of 0.3 were assumed; the correction factor for the stress in the center of the specimen was found to be 0.94 [14]. Strains and forces were measured in the longitudinal and transversal direction of the PBM to determine the moduli of elasticity in the longitudinal $\left(E_{y}\right)$ and transversal direction $\left(E_{x}\right)$ using Eq. (1) as shown in Fig. 2. $\left[\begin{array}{c}\varepsilon_{x} \\ \varepsilon_{y}\end{array}\right]=\left[\begin{array}{c}1 / E_{x}-v_{y x} / E_{y} \\ v_{x y} / E_{x}+1 / E_{y}\end{array}\right]\left[\begin{array}{c}\sigma_{x} \\ \sigma_{y}\end{array}\right]$,

where, $\varepsilon_{x}$ and $\sigma_{x}$ are strain and stress in the transversal direction, $\varepsilon_{y}$ and $\sigma_{y}$ are strain and stress in the longitudinal direction; $v_{x y}$ and $v_{y x}$ are the Poisson's ratios. Since both Poisson's ratios were assumed to be equal, only $v$ without the indices is used in the following.

To compare the modulus of elasticity from the biaxial with the uniaxial experiments, equivalent stress $\sigma_{\text {eq }}$ and equivalent strain $\varepsilon_{\text {eq }}$ were calculated using Eq. (2). The results are presented in Fig. 2. For instance in the case of the isotropic material, ethylene tetra fluoro ethylene (ETFE) foils and orthotropic material (pneumatic membranes reinforced with roven-woven fibers), it has been clearly shown in Refs. [9, 20] that, the stress-strain curve of uniaxial and biaxial testing condition was very alike. In a similar testing condition the results of the stress-strain curve was similar for PBM as well.

$$
\begin{aligned}
& \sigma_{\mathrm{eq}}=\left[\sigma_{x}^{2}+\sigma_{y}^{2}-\sigma_{x} \sigma_{y}\right]^{\frac{1}{2}} ; \\
& \varepsilon_{\mathrm{eq}}=\frac{1}{1+v}\left[\frac{1}{2}\left[\left(\varepsilon_{x}-\varepsilon_{y}\right)^{2}+\varepsilon_{x}^{2}+\varepsilon_{y}^{2}\right]\right]^{\frac{1}{2}},
\end{aligned}
$$

where, $\varepsilon_{x}$ and $\sigma_{x}$ are strain and stress in the transversal direction, $\varepsilon_{y}$ and $\sigma_{y}$ are strain and stress in the longitudinal direction; $v$ is the Poisson's ratio value.

\subsection{Uniaxial tension tests}

Uniaxial tension tests were conducted in the longitudinal direction of the PBM to determine the influence of displacement rate and temperature. 100, 75 and $50 \mathrm{~mm} / \mathrm{min}$ displacement rates were used in combination with 23,40 and $50{ }^{\circ} \mathrm{C}$ temperatures. The specimens were prepared according to the Swiss testing standard, with a central part of $40 \mathrm{~mm}$ width and $200 \mathrm{~mm}$ length and a nominal thickness of $5 \mathrm{~mm}$. Engineering stress and strain were determined instead of true stress and strain using Eq. (3), since the deformation of the peeling arm consider was in small range.

$\sigma=\frac{F}{\mathrm{Wt}} ; \quad \varepsilon=\frac{\Delta L}{L_{0}}$,

where, $F$ is the tension force, $W$ is the width, $t$ is the thickness, $\Delta L$ is the change in length and $L_{0}$ is the 

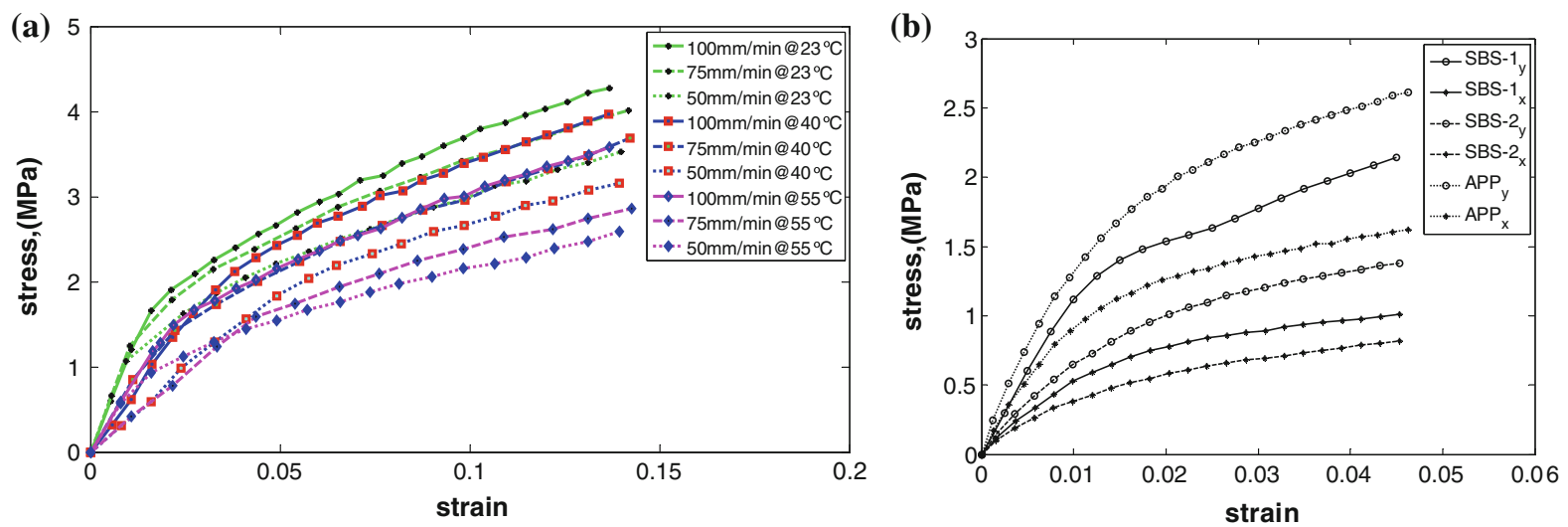

Fig. 3 a Influence of temperature and displacement rate (SBS-1). b Uniaxial stress-strain curve for three different types of PBM at $23{ }^{\circ} \mathrm{C}$

length before deformation. Examples of the stressstrain curve performed at $23{ }^{\circ} \mathrm{C}$ for SBS-1 material in the longitudinal direction are shown in Fig. 3a. Additional experiments were conducted on all three types of the waterproofing membranes at $23{ }^{\circ} \mathrm{C}$ in both longitudinal and transversal direction as presented in Fig. 3b.

\subsection{Blister test}

To investigate adhesive blister propagation, sand blasted square concrete plates of $500 \times 500 \mathrm{~mm}$ with water inlet size of $17 \mathrm{~mm}$ diameter were prepared and PBM were welded on top of it as explained by Hailesilassie and Partl [14]. The specimens were stored at $23{ }^{\circ} \mathrm{C}$ room temperature for more than $24 \mathrm{~h}$ and the temperature in the PBM was checked using a thermocouple prior to testing. For safety reasons water instead of gas was used to produce blisters artificially between the PBM and the concrete plate, being well aware that in reality not water but vapor would cause pressure and blister propagation. The pressure was controlled with a manometer and increased at $3.3 \mathrm{kPa} /$ $\mathrm{s}$ for $60 \mathrm{~s}$ until it reached $0.2 \mathrm{MPa}$ and then kept constant at $0.2 \mathrm{MPa}$ during the blister growth for all types of the PBM.

Digital image correlation experimental technique was used to measure the adhesive blister propagation as described by Galliot and Luchsinger [19]. This experimental technique was found useful to measure deformation fields at the surface of objects under any kind of loading condition [9]. To generate the $3 \mathrm{D}$ views and contour maps of the vertical deflection of the blisters in $z$-direction, post processing software (Vic-3D 2009) was used. Examples of reconstructed images taken during loading are shown in Fig. 4a, b. Similarly the blister height and radius with time for the three different types of PBM were measured during the blister propagation as indicated in Fig. 5.

During the first $60 \mathrm{~s}$ of loading, bulging of the blister was detected and the change in blister radius remained zero, whereas the blister height was increasing up to $6.8,7.1$ and $2.3 \mathrm{~mm}$ for the SBS-1, SBS-2 and APP membranes, respectively, as shown in Fig. 6a, b. Since the growth rate of the blister propagation was slow, one image per second was used to measure the blister growth in all experiments. The final blister height was measured using a ruler at the end of each experiment to check with the data from the digital image correlation experiment. The comparison between the digital image correlation and the measured value showed an error of about $4.25 \%$.

\subsection{Peeling test}

The purpose of this experiment and analysis is to determine the peeling fracture energy as a second method to compare with the fracture energy from analytical blister equation. Sand blasted square concrete plates of $500 \times 500 \mathrm{~mm}$ were prepared to investigate the peeling fracture energy. In order to increase the bond between the concrete and the PBM membrane, a primer of SBS modified bitumen dissolved in toluene was applied on the concrete surface 
Fig. 4 a 3D view of the blister. $\mathbf{b}$ Top view of vertical deflection in $z$ direction showing elliptical adhesive debonding contour on the membrane and symbols for theoretical modeling [14]
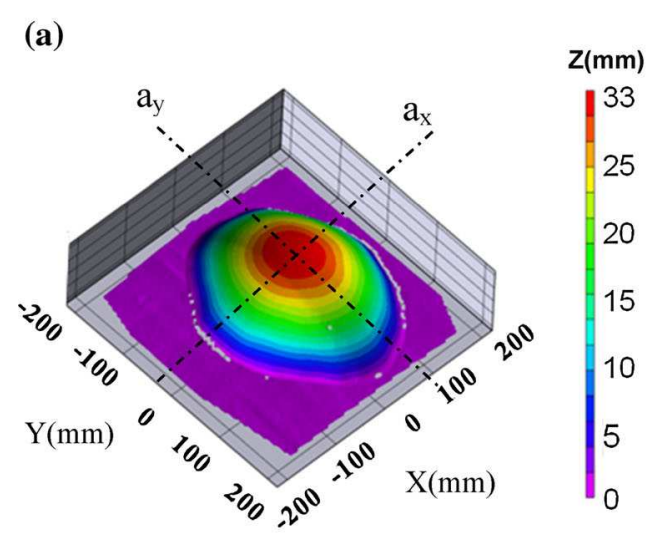

(a)

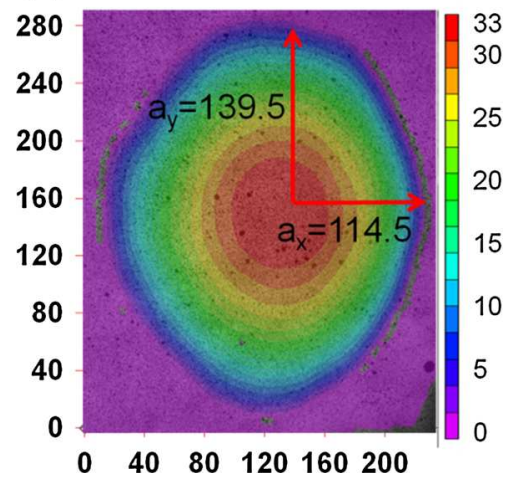

(b)

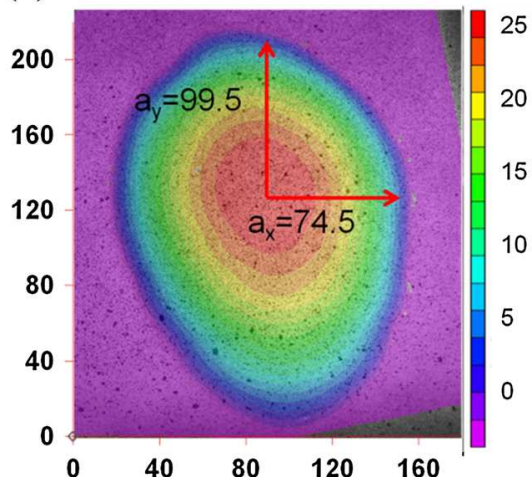

(b)

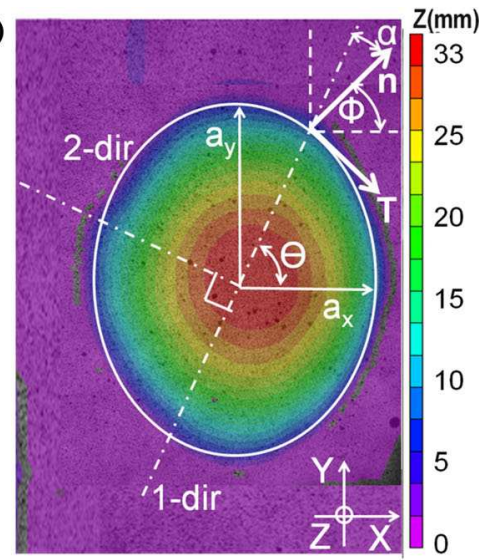

(c)

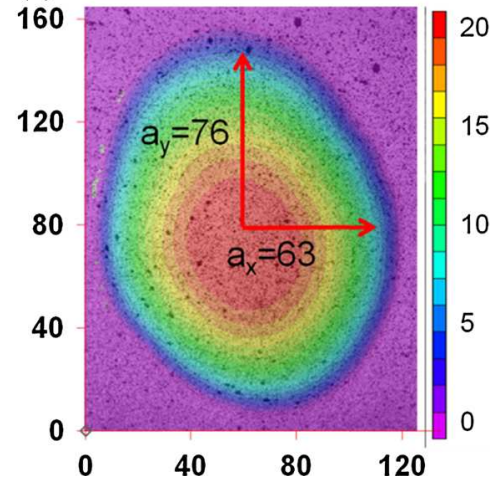

Fig. 5 Top view of elliptical blister contour and vertical deflection in $z$-direction of PBM a SBS-1, b SBS-2 and c APP

Fig. 6 a Measured blister height with time, b blister radius in longitudinal $(y)$ and transversal $(x)$ direction with time. Also shown are the values at $70 \mathrm{~s}$ used as a reference for calculation (see Table 4)
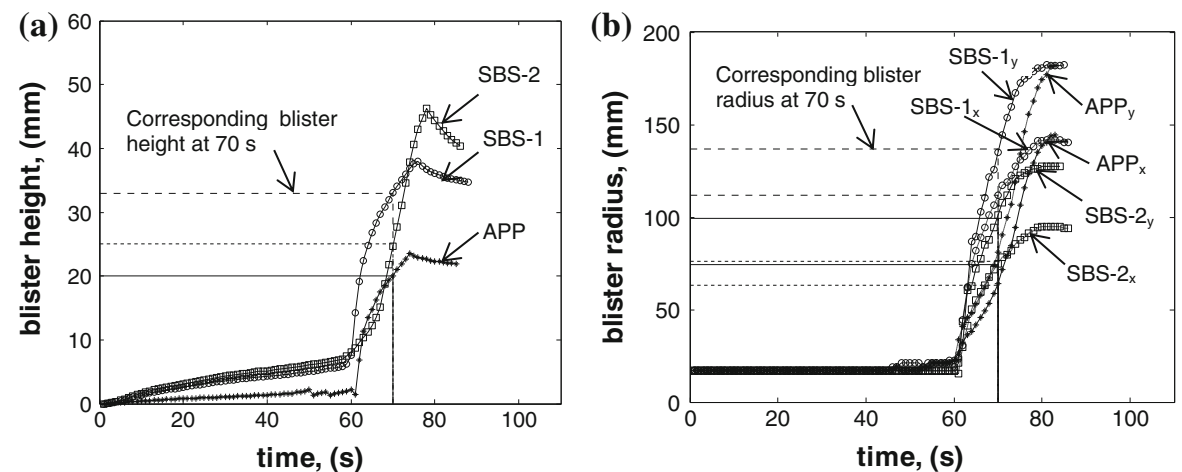

prior to welding the PBM, as shown on Fig. 7a. The membranes were applied on each concrete plate using an open gas torch without air supply into the nozzle, as indicated in Fig. 7b. Great care was given to achieve uniform welding and reduce the most unfavorable heat effect by keeping the distance between the membrane surface and the flame as well as the speed of torching for the peeling test specimens as constant as possible. The concrete plates were cut to a size of $50 \times 350 \mathrm{~mm}$. The setup of the peeling test is shown in Fig. 7c. The specimens were conditioned at target temperature for more than $24 \mathrm{~h}$ and the temperature in the PBM layer was checked using a thermocouple prior to testing. An aluminum grip was used on each side of the specimen 
Fig. 7 a Primer applied on the concrete plate, $\mathbf{b}$ welding of the PBM on the concrete plate and $\mathbf{c}$ peeling test set up

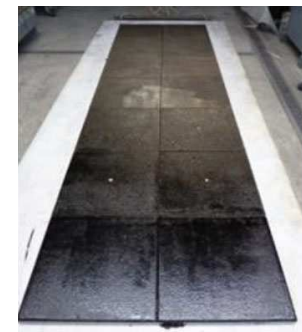

(a)

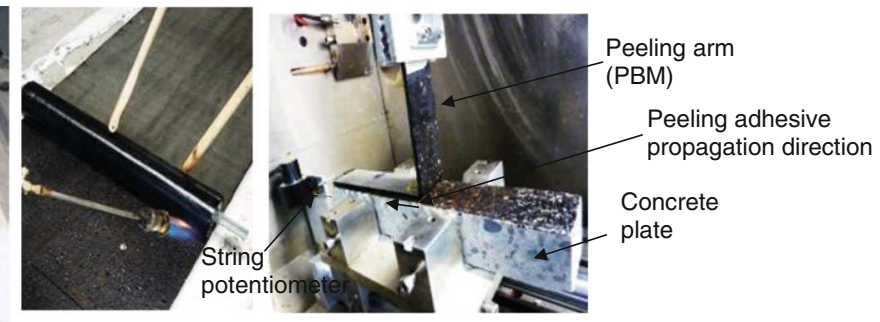

(b) (c)
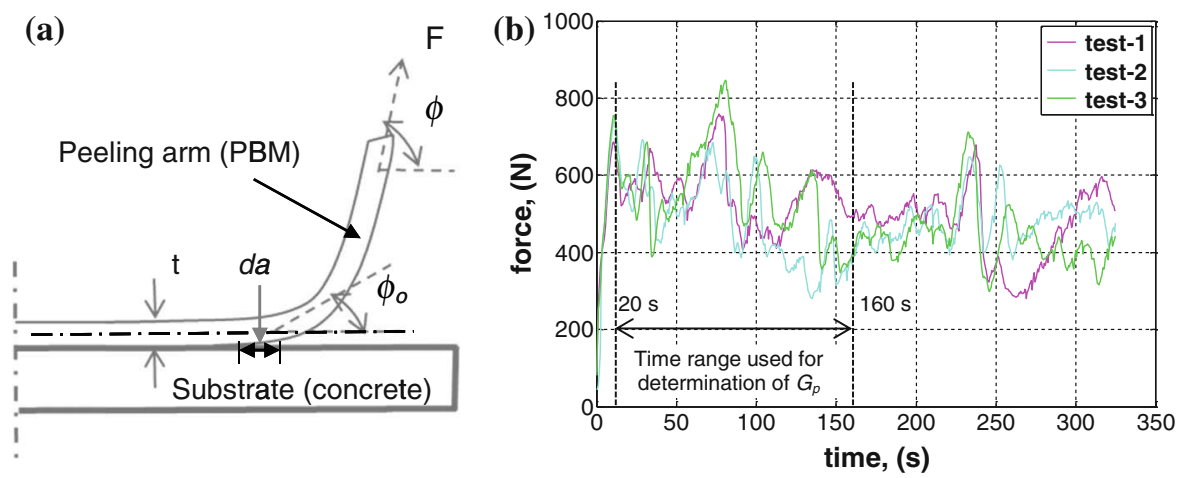

Fig. 8 a Schema of peeling test with symbols for theoretical modeling and $\mathbf{b}$ typical peeling force versus time graph

to fix the rail which is mounted on linear bearings that moves freely. The peeling crack growth was measured using string potentiometer, WDS-1500-P60-CR which has a measuring range of $1,500 \mathrm{~mm}$ and with integrated cable was attached to the specimen, the setup is shown in Fig. 7c. The crack propagation length was measured every $0.5 \mathrm{~s}$.

Peeling failure occurs from loss of interfacial bonding force. Hence, this type of failure may be related to the work of adhesion, the work of cohesion or some complicated combination of both [10]. However, note that the above terms are based on the macroscopic interpretation of the interfacial fracture process since, on microscopic scale, adhesive fracture cannot occur [10]. The peeling test is shown schematically in Fig. 8a with symbols for theoretical modeling of the debonding, i.e. crack growth, rate and calculation of the adhesive fracture energy for peeling. The typical peeling force versus time graph in Fig. $8 \mathrm{~b}$ was obtained by peeling at $100 \mathrm{~mm} / \mathrm{min}$ displacement rate and $23{ }^{\circ} \mathrm{C}$ conditioning temperature. The high levels of the peeling force is considered to come from a cohesive fracture in the peeling arm and the low levels from adhesive fracture between the substrate and adhesive layer [11].

\subsubsection{Fracture energy determination of the peeling test}

In order to analyze the fracture energies of the peeling test it is necessary to conduct both the uniaxial tension test and the peeling test $[10,11]$. The fracture energies of the peeling test depend on the rate of peeling force and the testing temperature. The energy balance of the system when a crack propagates between the substrate and the membrane is described in Eq. (5) [10, 11, 21]. Since the peeling test is done at $90^{\circ}$ peeling angle, which creates a bending deformation at the crack front, thus the equation considers the plastic bending energy in the crack front to determine the peeling fracture energy, $G_{\mathrm{p}}$. But in the case of the blister test since the in plane peeling forces are acting at small angle of peeling, therefore it is not relevant to consider plastic bending. In order to eliminate the kinetic energy associated with moving peeling fracture, it is necessary to conduct a slow peeling test. For this reason displacement rates of 50,75 and $100 \mathrm{~mm} / \mathrm{min}$ are used. As demonstrated in Fig. 3, the uniaxial tests strained the waterproofing membrane beyond the yielding point and further increase in stress produces additional plastic deformation. This indicates that the 

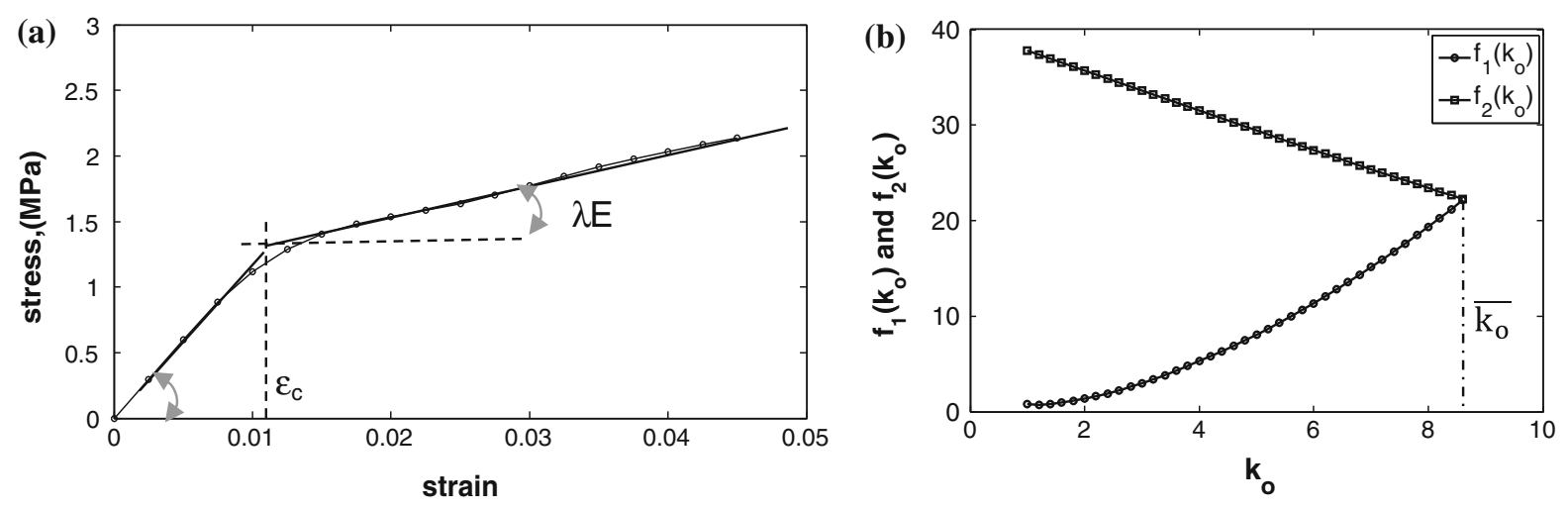

Fig. 9 a Typical stress versus strain curve of uniaxial test and $\mathbf{b}$ convergence curve of Eqs. (8) and (9)

waterproofing membrane follows bilinear material behavior with work hardening. Therefore, from the uniaxial test, it is possible to determine the modulus of elasticity $(E)$, the yield strain $\left(\varepsilon_{\mathrm{c}}\right)$ and the work hardening parameter $(\lambda)$ as shown in Fig. 9a. The adhesive fracture energy for peeling is calculated from Eq. (4),

$G_{\mathrm{p}}=G^{\mathrm{e}}-G^{\mathrm{b}}$,

where $G^{\mathrm{e}}$ is the energy accounts for elastic tensile deformation and elastic bending of the peel arm and $G^{\mathrm{b}}$ accounts for plastic bending energy in the crack front.

The energy balance equation for crack propagation reads.

$G_{\mathrm{p}}=\frac{1}{W}\left(\frac{\mathrm{d} U_{\mathrm{App}}}{\mathrm{d} a}-\frac{\mathrm{d} U_{\text {strain }}}{\mathrm{d} a}-\frac{\mathrm{d} U_{\mathrm{d} t}}{\mathrm{~d} a}-\frac{\mathrm{d} U_{\mathrm{d} b}}{\mathrm{~d} a}\right)$,

where $U$ is an energy term, $W$ is the width of peel arm, $a$ is the crack length and the suffices App, strain, $\mathrm{d} t$ and $\mathrm{d} b$ refer to the applied load, strain, dissipation in tensile deformation and dissipation in bending near the peel front.

The above energy terms from Eq. (5) which contains the elastic deformation can be rearranged as follows [11, 21].

$$
\begin{aligned}
G_{\mathrm{a}}^{\infty E} & =\frac{1}{W}\left(\frac{\mathrm{d} U_{\mathrm{App}}}{\mathrm{d} a}\right)=\frac{F}{W}(1-\cos (\phi)) ; \\
G_{\max }^{\mathrm{e}} & =\frac{1}{W}\left(\frac{\mathrm{d} U_{\mathrm{d} t}}{\mathrm{~d} a}\right)=\frac{t E \varepsilon^{2}}{2} ; \frac{1}{W}\left(\frac{\mathrm{d} U_{\text {strain }}}{\mathrm{d} a}\right)=\frac{F \varepsilon}{W}, \\
G^{\mathrm{e}} & =\frac{F}{W}(1+\varepsilon-\cos (\phi))-\frac{t E \varepsilon^{2}}{2},
\end{aligned}
$$

where $F$ is the mean peeling force, $W$ is the width of peeling arm, $\varepsilon$ is the strain in the peeling arm, $\phi$ is the angle of peeling, $E$ is the modulus of elasticity of the membrane from the uniaxial test, $t$ is the thickness of the membrane. The mean peeling force, $F$ is determined as average value in the time frame between 20 and $160 \mathrm{~s}$, where the peeling fracture propagation is at steady state as shown in Fig. 8b. Similar procedure has been used in Swiss standard to determine the peeling force [22]. This time range is selected since at the beginning of the peeling time, the crack propagation didn't commence hence it does not represent the adhesive property. In addition this study focuses on peeling crack propagation not on the adhesive crack initiation.

The deformation process on the crack front was modeled using large displacement beam theory which involves only elastic theory [23]. The peeling fracture propagation energy from the external applied force, for infinite tensile stiffens and zero bending modulus is denoted as $G_{\mathrm{A}}^{\infty E}$ as shown in Eq. (6). The maximum elastic fracture energy which can be stored in the peeling arm is denoted as $G_{\max }^{\mathrm{e}}$ as indicated in Eq. (6). Note that $f_{1}\left(\overline{k_{0}}\right)$, in Eq. (7) equals to $f_{2}\left(\overline{k_{0}}\right)$ defined in Eq.(8). The general scheme of similar modeling of the local bending was shown by Refs. [10, 13, 23]. As it is stated in the above references, iteration needs to be performed by substituting the values of $k_{0}$ in Eq. (7) and (8) starting from zero until the two equations converge to the same value. As indicated in Fig. $9 \mathrm{~b}$ the equations converged at the value of $\overline{k_{0}}$, which relates the elastic maximum energy, $G_{\max }^{\mathrm{e}}$ with plastic bending energy, $G^{\mathrm{b}}$.

$$
\frac{G_{\mathrm{A}}^{\infty E}}{G_{\max }^{\mathrm{e}}}=\frac{(1-\cos \phi)}{\left[1-\cos \left(\phi-\phi_{0}\right)\right]} f_{1}\left(\bar{k}_{0}\right) ; \quad \phi_{0}=\frac{4 \varepsilon_{c} k_{0}}{3},
$$




$$
\begin{aligned}
f_{2}\left(\bar{k}_{0}\right)= & \frac{\lambda}{3}\left[1+4(1-\lambda)^{2}\right] k_{0}^{2}+2(1-\lambda)^{2}(1-2 \lambda) k_{0} \\
& +\frac{8}{3} \frac{(1-\lambda)^{4}}{(1-2 \lambda) k_{0}}-4(1-\lambda)^{3}
\end{aligned}
$$

where $G_{\mathrm{A}}^{\infty E}$ is the peeling fracture propagation energy when infinite tensile stiffens and zero bending stiffness is considered, $\phi_{0}$ is the theoretical root angle at the crack front as indicated in Fig. 8a.

The parameter $\overline{k_{0}}$ is determined for different types of waterproofing membranes as shown in Table 6. After determining the value of $\overline{k_{0}}$, the strain energy which accounts for local plastic bending near the crack front of the membrane can be calculated using Eq. (9). In the region of plastic deformation at the crack front, the maximum elastic energy is related to plastic bending energy using $f\left(\overline{k_{0}}\right)$ presented in Eq. (10) [10, $11]$.

$G^{\mathrm{b}}=\frac{1}{W}\left(\frac{\mathrm{d} U_{\mathrm{d} b}}{\mathrm{~d} a}\right)=G_{\max }^{\mathrm{e}} f\left(\bar{k}_{0}\right) ; \quad G_{\max }^{\mathrm{e}}=\frac{E t \varepsilon_{\mathrm{c}}^{2}}{2}$,

where $G_{\max }^{\mathrm{e}}$ is the maximum elastic fracture energy, $f\left(\overline{k_{0}}\right)$ is a factor relating the maximum elastic fracture energy and plastic bending energy, $G^{\mathrm{b}}$.

$$
\begin{aligned}
f\left(\bar{k}_{0}\right)= & \frac{4}{3} \lambda(1-\lambda)^{2} \bar{k}_{0}^{2}+2(1-\lambda)^{2}(1-2 \lambda) \bar{k}_{0} \\
& +\frac{2}{3} \frac{(1-\lambda)}{(1-2 \lambda) \bar{k}_{0}}\left[1+4(1-\lambda)^{3}\right] \\
& -(1-\lambda)\left[1+4(1-\lambda)^{2}\right] .
\end{aligned}
$$

\section{Results and discussion}

\subsection{Blister test}

When comparing between the mean values of stressstrain curve from uniaxial and biaxial test shown in Fig. 2, the two testing methods gave comparable results for SBS-1. The standard deviation values were determined as indicated in Fig. 2 close to the first yielding point for elastic deformation (at $1 \%$ strain) and at strain of $3 \%$ where plastic deformation would occur in the specimens. The standard deviation analysis showed that elastic modulus deviates from the mean value between 0.16 and $0.23 \mathrm{MPa}$ for uniaxial and 0.09-0.2 MPa for biaxial tests as shown in Fig. 2. The ratios $E_{y} / E_{x}$ between the modulus of elasticity in longitudinal and transversal direction are
Table 2 Ratio of modulus of elasticity of SBS and APP membranes

\begin{tabular}{lllll}
\hline Loading condition & \multicolumn{2}{l}{ Uniaxial } & Biaxial \\
\cline { 2 - 4 } PBM types & SBS-1 & SBS-2 & APP-1 & SBS-1 \\
\hline$E_{y} / E_{x}$ & 1.44 & 1.34 & 1.35 & 1.43 \\
\hline
\end{tabular}

Table 3 Modulus of elasticity of SBS and APP membranes from uniaxial tension tests

\begin{tabular}{llll}
\hline Modulus (MPa) & SBS-1 & SBS-2 & APP-1 \\
\hline$E_{x}$ & 57.3 & 38.6 & 62.2 \\
$E_{y}$ & 82.5 & 51.6 & 84.0 \\
\hline
\end{tabular}

indicated in Table 2. The result indicates that the elastic modulus ratio for SBS-1 determined in the biaxial test is comparable to the value from the uniaxial test.

Since for SBS-1 the ratio between the modulus of elasticity from biaxial test was found to be comparable to the uniaxial loading condition, the uniaxial test moduli were used for determining the blister propagation energy $G$. The uniaxial test results shown in Fig. $3 b$ are used to determine the moduli of elasticity $E_{y}$ and $E_{x}$ in the longitudinal and transversal direction as presented in Table 3. The experiments were done at conditioning temperature of $23{ }^{\circ} \mathrm{C}$ and at $50 \mathrm{~mm} / \mathrm{min}$ displacement rate.

According to the results of the digital image correlation measurements in Fig. 5, an elliptical adhesive propagation front was observed for the three different types of waterproofing membranes. However, in some cases an exact elliptical crack propagation front may not occur because of non-uniform adhesion between the concrete plate and the PBM. Since the blister propagation front resembles an elliptical shape, an elliptical adhesive propagation model was used to determine the propagation energies of these different types of the PBM. Details of the equation are presented by Hailesilassie and Partl [14].

The energy balance for adhesive blister propagation is described in Eq. (11) as the sum of the potential energies of the external applied load (negatively defined) and the elastic strain energy stored in the membrane depending on the geometry of the adhesive failure zone [24, 25]. 
$G_{\mathrm{b}} \cong-\left.\left(\frac{\partial W_{\text {app }}}{\partial A}+\frac{\partial U_{\text {strain }}}{\partial A}\right)\right|_{p}$,

where $A$ is elliptic adhesive failure area, $W_{\text {app }}$ is work done and $U_{\text {strain }}$ is membrane's strain energy

The fracture energy release rate $G_{\mathrm{b}}$, is the difference between the work done $W_{\text {app }}$ by the pressurized water in the blister and the membrane's strain energy $U_{\text {strain }}$ [24-26] and thus describes the adhesive blister propagation energy release rate [14]. $G$ is defined per unit width along the elliptic failure front between the PBM and the concrete and has a unit of $\mathrm{J} / \mathrm{m}^{2}$. Hence, for an elliptical blister with an elliptic adhesive failure area $A, G$ is given by the following Eq. (12).

$$
\begin{aligned}
G_{\mathrm{b}} & =\frac{p^{2} k_{\mathrm{s}} a_{x}^{3} a_{y}^{3} \pi}{h k E_{x} t c_{\mathrm{eli}}} \sqrt{\frac{k_{1} k^{2}}{a_{y}^{4}}+\frac{k_{2}}{a_{x}^{4}}}, \\
k & =\frac{E_{y}}{E_{x}}, k_{1}=\frac{\cos (\theta)^{2}}{\cos (\alpha)^{2} \sin (\beta)^{2}} \\
& \text { and } k_{2}=\frac{\sin (\theta)^{2}}{\cos (\alpha)^{2} \sin (\beta)^{2}},
\end{aligned}
$$

where $E_{x}$ is the transversal modulus of elasticity in $x$ direction, $E_{y}$ is the longitudinal moduli of elasticity in $y$-direction, $a_{x}$ and $a_{y}$ are the minor and major axes of the blister adhesive failure front; $\theta$ is the angle of rotation; $h$ is the blister height; $t$ is the thickness of the water proofing membrane; $p$ is the applied pressure; $k_{\mathrm{s}}$ is the shape factor; $C_{\text {eli }}$ is the circumference of the elliptical crack front; $\alpha$ is the angle difference between the normal $n$ and the rotation angle $\theta$ according to Fig. $4 \mathrm{~b} . \beta$ is the angle between the normal and vertical stress. $k, k_{1}$ and $k_{2}$ are constant terms which are a function of angles as described above.

The adhesive blister propagation energy can be calculated using Eq. (12) irrespective of the angle $\theta$. Any angle $\theta$ from $0^{\circ}$ to $360^{\circ}$ can be used for values of $k_{1}$ and $k_{2}$. Angle $\theta$ equal to zero was used in this case to determine the propagation energy from Eq. (12). The radius $a_{x}, a_{y}$ and the blister height $h$ at any of this time can be taken, in this particular case parameters are taken at $70 \mathrm{~s}$ as shown in Fig. 6a and Table 4, including other parameters to calculate the adhesive blister propagation energy for the three types of PBM. The blister propagation rate in the longitudinal direction, $V_{\mathrm{Gb}}$ was determined from Fig. $6 \mathrm{~b}$, and presented in Table 4.
Table 4 Parameters used to calculate the adhesive blister propagation energy $G_{\mathrm{b}}$ and blister crack propagation rate $\left(V_{\mathrm{Gb}}\right)$

\begin{tabular}{llll}
\hline Parameters & SBS-1 & SBS-2 & APP \\
\hline$E_{x}(\mathrm{MPa})$ & 57.3 & 38.6 & 62.2 \\
$a_{x}(\mathrm{~mm} @ 70 \mathrm{~s})$ & 114.5 & 74.5 & 63 \\
$a_{y}(\mathrm{~mm} @ 70 \mathrm{~s})$ & 139.5 & 99.5 & 76 \\
$h(\mathrm{~mm} @ 70 \mathrm{~s})$ & 33.0 & 25 & 20 \\
$c_{\mathrm{eli}}(\mathrm{mm})$ & 797.56 & 549.5 & 436.5 \\
$t(\mathrm{~mm})$ & 5.0 & 5.0 & 5.0 \\
$p(\mathrm{MPa})$ & 0.2 & 0.2 & 0.2 \\
$k$ & 1.44 & 1.34 & 1.35 \\
$k_{1}$ for $\theta=0^{\circ}$ & 4 & 4 & 4 \\
$k_{\mathrm{s}}$ & 0.543 & 0.543 & 0.543 \\
$k_{2}$ for $\theta=0^{\circ}$ & 0 & 0 & 0 \\
$G_{\mathrm{b}}\left(\mathrm{J} / \mathrm{m}^{2}\right)$ & 8,627 & 4,241 & 1,906 \\
$V_{\mathrm{Gb}}(\mathrm{mm} / \mathrm{s})$ & 13.7 & 9.95 & 7.6 \\
\hline
\end{tabular}

\subsection{Peeling test}

As shown previously in Fig. 3a, the elastic modulus for a specific testing temperature and displacement rate were determined from the uniaxial tension test. From these tests it was observed that the temperature has more influence than the displacement rate on modulus of elasticity of the SBS-1 water proofing membrane. After the yielding point, the influence of the displacement rate was noticeable for all testing temperatures. As mentioned before, the mean peeling force $F$ was used in the 20-160 s time frame in Eq. (5) to determine the energy needed during elastic elongation of the peeling arm. To investigate the influence of temperature and displacement rate on the peeling fracture energy $G_{\mathrm{p}}$ of the SBS-1 membrane, Eqs. (5), (6) and (10) were used. Fracture energy results for elastic deformation $G^{\mathrm{e}}$, plastic bending deformation, $G^{\mathrm{b}}$ and adhesive fracture energy of the peeling, $G_{\mathrm{p}}$, respectively are presented in Table 5 for different temperatures and displacement rates. The adhesive fracture energy is also shown in Fig. 10a for different temperatures and displacement rates. The results indicate that the fracture energy for peeling decreased considerably with increasing temperature whereas the influence of the displacement rate is not obvious. In addition to this, the displacement rate at the specific temperatures has insignificant influence on the fracture energy value for higher temperatures compared to lower temperatures. The crack growth rate was 
Table 5 Fracture energy values at different displacement rates and temperatures

\begin{tabular}{|c|c|c|c|c|c|c|c|c|c|}
\hline \multirow{2}{*}{$\begin{array}{l}\text { Temperature }\left({ }^{\circ} \mathrm{C}\right) \\
\text { Displacement } \\
\text { rate }(\mathrm{mm} / \mathrm{min})\end{array}$} & \multicolumn{3}{|l|}{23} & \multicolumn{3}{|l|}{40} & \multicolumn{3}{|l|}{55} \\
\hline & 50 & 75 & 100 & 50 & 75 & 100 & 50 & 75 & 100 \\
\hline$G^{\mathrm{e}}\left(\mathrm{J} / \mathrm{m}^{2}\right)$ & $12,809.7$ & $15,840.3$ & $16,875.8$ & $7,760.6$ & $9,361.9$ & $9,750.9$ & $5,250.1$ & $6,717.5$ & $6,549.7$ \\
\hline$G^{\mathrm{b}}\left(\mathrm{J} / \mathrm{m}^{2}\right)$ & $5,513.2$ & 6,849 & $6,319.2$ & $3,524.3$ & $4,757.5$ & $4,270.7$ & $2,763.4$ & 3,474 & $2,680.5$ \\
\hline$G_{\mathrm{p}}\left(\mathrm{J} / \mathrm{m}^{2}\right)$ & $8,626.5$ & $9,500.3$ & $10,556.6$ & $4,236.4$ & $4,604.4$ & $5,480.3$ & $2,486.8$ & $3,243.5$ & $3,869.2$ \\
\hline$V_{\mathrm{Gp}}(\mathrm{mm} / \mathrm{s})$ & 0.86 & 1.21 & 1.62 & 0.73 & 1.19 & 1.53 & 0.72 & 1.07 & 1.48 \\
\hline
\end{tabular}
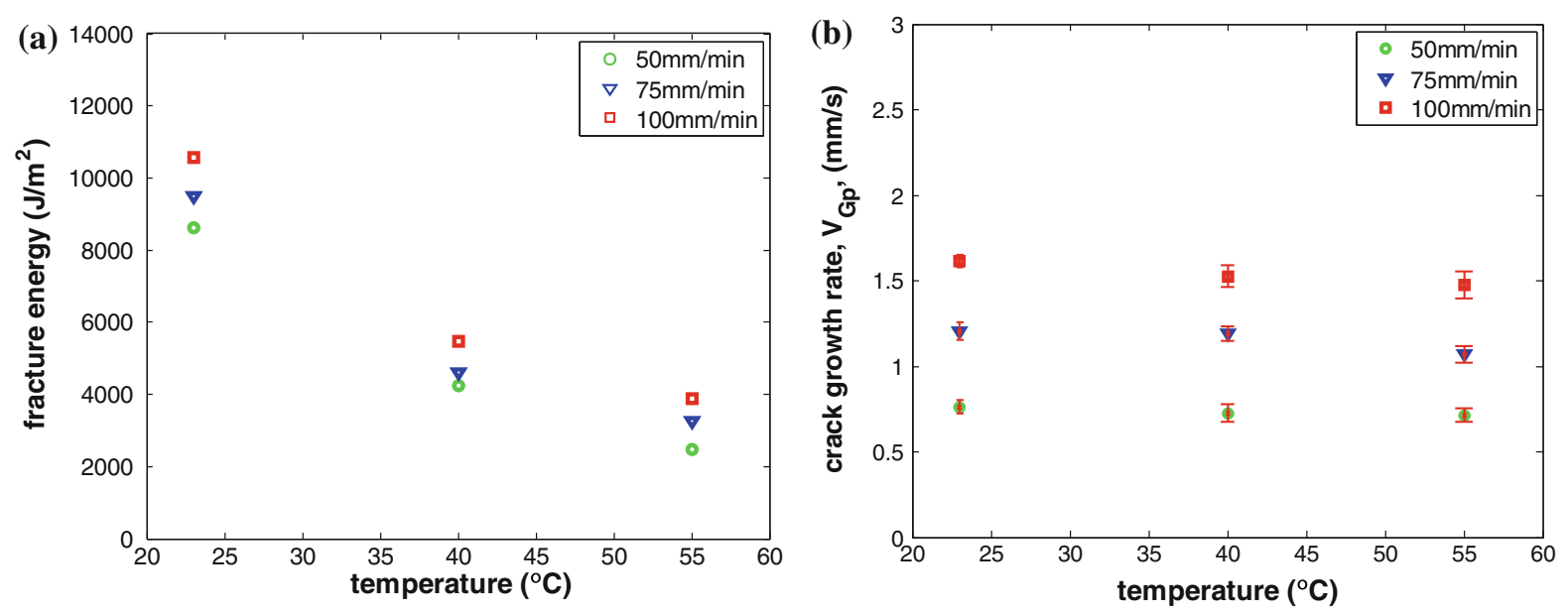

Fig. 10 a Peeling fracture energy and $\mathbf{b}$ crack growth rate at different temperature and displacement rate

measured using string potentiometer during the peeling test. The direction of the crack propagation is shown in Fig. 7c. As indicated in Fig. 10b, the crack growth rate did not change significantly with increasing temperature. Nevertheless, increasing the displacement rate at specific temperature increased the crack growth rate significantly. From Fig. 10a, b, it is obvious that the adhesive fracture energy for peeling was clearly less dependant on displacement rate than the crack growth rate.

\subsection{Comparison between the peeling and blister test}

For comparing and ranking the adhesive properties of the membranes, the modulus of elasticity of SBS-1, SBS-2 and APP waterproofing membranes were determined in uniaxial tension tests at a temperature of $23{ }^{\circ} \mathrm{C}$ and a displacement rate of $50 \mathrm{~mm} / \mathrm{min}$ (Table 3). Peeling experiments were conducted as well at $23{ }^{\circ} \mathrm{C}$ and $50 \mathrm{~mm} / \mathrm{min}$ displacement rate.
Blister tests were performed at $23{ }^{\circ} \mathrm{C}$ increasing the pressure at $3.3 \mathrm{kPa} / \mathrm{s}$ for $60 \mathrm{~s}$ until it reached $0.2 \mathrm{MPa}$ and then keeping it constant at $0.2 \mathrm{MPa}$ during the blister growth. Comparing the blister crack propagation rate, $V_{\mathrm{Gb}}$ from Table 4 and the peeling crack propagation rate, $V_{\mathrm{Gp}}$ from Table 5 (for $23{ }^{\circ} \mathrm{C}$ and $50 \mathrm{~mm} / \mathrm{min}$ displacement rate), the blister crack growth rate was about a factor of 15 faster than the cracking rate in the peeling test. However, as indicated in Fig. 10a, b the influence of the loading speed on fracture energy according to peeling test results was found to be comparatively small, a comparison between peeling and blister test fracture energies and the corresponding ranking appeared justified.

Comparison between SBS-1, SBS-2 and APP fracture energy from blister and peeling tests indicates that SBS-1 has a higher value compared to the other types of the membranes as indicated in Tables 4 and 6 . The SBS-2 membrane has lower fracture energies compared to SBS-1, the reason for this can be the presence of sand layer on the bottom of the membrane 
Table 6 Parameters used to calculate the peeling fracture energy $G_{\mathrm{p}}$

\begin{tabular}{lccc}
\hline Parameters & SBS-1 & SBS-2 & APP \\
\hline$E_{\mathrm{y}}(\mathrm{MPa})$ & 82.5 & 51.6 & 84.1 \\
$\lambda$ & 0.18 & 0.40 & 0.29 \\
$\varepsilon(\%)$ & 35.0 & 10.0 & 2.7 \\
$F(\mathrm{~N})$ & 527.0 & 221.45 & 116.7692 \\
$\overline{k_{0}}$ & 7.3 & 2.0 & 5.6 \\
$G_{\mathrm{p}}\left(\mathrm{J} / \mathrm{m}^{2}\right)$ & $8,180.0$ & $3,236.0$ & $1,591.9$ \\
$V_{\mathrm{Gp}}(\mathrm{mm} / \mathrm{s})$ & 0.89 & 0.6 & 0.45 \\
\hline
\end{tabular}

affects the good adhesion of the PBM and the concrete. The reason for the lower fracture energies of APP can be attributed to the different polymer modified binder properties.

It can be seen from Fig. 11a that the blister propagation energies $G_{\mathrm{b}}$ from the blister test Eq. (12) and the fracture energy $G_{\mathrm{p}}$, where the equation was adopted from Refs. [10, 13, 23], from the peeling test are comparable. From this, it can be concluded that, in principle, by knowing the pressure inside the blister, it is possible to use the blister propagation equations and estimate the energy required to initiate blister growth. In this way, one can also iteratively calculate back the peeling force correlated to the fracture energy. This helps to investigate susceptibility of membranes for blister formation by conducting peeling test instead of using complicated and time consuming blister tests. In order, to confirm these findings, however, further tests are needed. As indicated in Fig. 11b, the crack growth rate of blister propagation is higher compared to the peeling crack propagation, nevertheless, as shown in Fig. $10 \mathrm{~b}$, when the crack growth rate for $23{ }^{\circ} \mathrm{C}$ increased from 0.86 to $1.62 \mathrm{~mm} / \mathrm{s}$, all most doubled, the peeling fracture energy only increased by small amount as indicated in Fig. 10a. Therefore, higher crack growth rate of the blister propagation may not have significant influence on the comparison between the fracture energy of the blister and the peeling tests.

\section{Conclusions}

When placing hot mix asphalt pavements on concrete bridges or in cases of extended exposure of the waterproofing protection layer to the sun because of significant construction delays, blistering my occur between the PBM and the concrete surface of the bridge deck, from steam pressure accumulation. Such pressure creates a multi-axial stress state in the PBM which has orthotropic material properties.

This paper focuses on test methods for comparing the adhesive properties of PMBs by means of the analytical blister propagation energy and its comparison with a standard peeling test method in fracture mechanics approach. The results from peeling fracture energy of all the three membranes indicated that the blister propagation energy is within the range of peeling fracture energy. The fracture energy comparison between the two methods indicated that the blister propagation model approach works well for modeling blister growth and propagation. Nevertheless, conducting blister test for investigating the adhesive properties of the PBM can be difficult and time consuming, because of careful determination of the parameters for the model. By conducting peeling and uniaxial tests, it is possible to relate the peeling force to the peeling fracture energy of the PBM. Peeling
Fig. 11 a Comparison of the fracture energy at $23{ }^{\circ} \mathrm{C}$ between the peeling (p) and the blister test (b) for different types of PBM and b corresponding crack growth rate for different types of PBM at $23{ }^{\circ} \mathrm{C}$ temperature
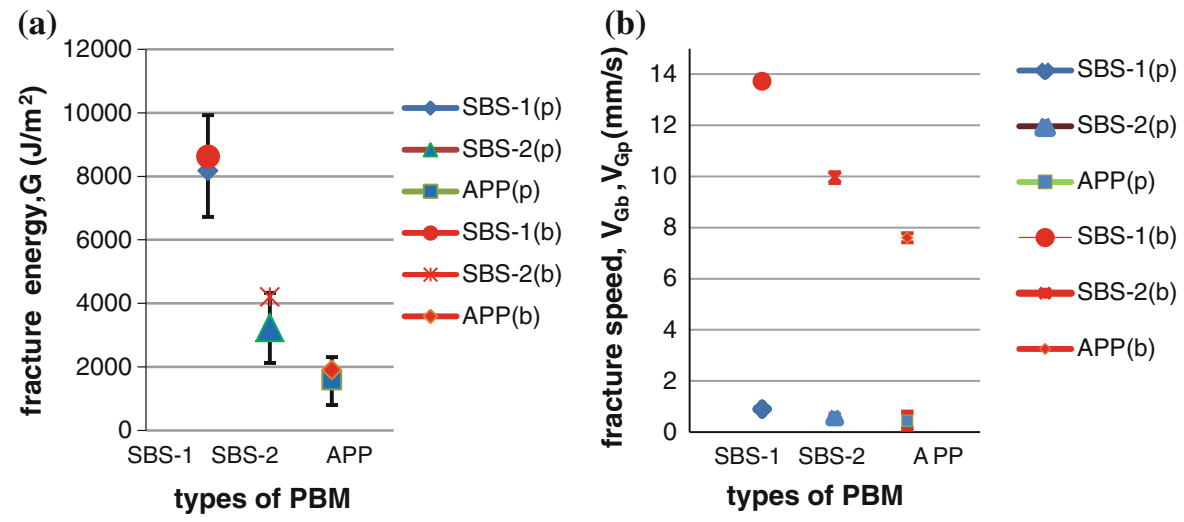
crack propagation energy showed only little dependency on the crack growth rate and was more influenced by temperature. From this it was concluded that the comparison between the peeling fracture energy and blister propagation energy is less influenced by the displacement rate of peeling test and blister growth rate than by the testing temperature.

The modulus of elasticity in the longitudinal and transversal direction of the PBM determined in this study indicated that in case of SBS, the biaxial extension and standard uniaxial tension test produce comparable strain-stress curve in the elastic range. The equivalent stress-strain curve from a biaxial experiment was similar to the uniaxial stress-strain curve in the longitudinal direction.

Formation of blisters under waterproofing membranes on concrete bridge decks is caused by a complex mechanism which certainly needs further attention and research efforts. However, principles found and shown here appear promising and may serve as an element for both more reliable practical tools for assessing the adhesive properties of PMBs and improved theoretical understanding and characterization of the mechanisms of blister formation that are known to trigger severe and expensive long term damage of bridge deck structures.

Acknowledgments The authors acknowledges the support of colleges Kienast Hans and Kato Hiroyuki, Road Engineering/ Sealing Components, EMPA (Swiss Federal Laboratories for Material Science and Technology) including other group members of the Lab. and C. Galliot, Center for Synergetic Structures, EMPA, for his many interactions throughout the project.

\section{References}

1. Hailesilassie BW, Partl MN (2012) Mechanisms of asphalt blistering on concrete bridges. J ASTM Int 9. doi:10.1520/ JAI104135

2. Partl MN, Gubler R, Hean S (2001) Belagsschäden infolge Blasenbildung auf einer neuen Hängebrücke in Hongkong. In: Muster W, Schläpfer Herausgeber K (eds) Nachhaltige Material- und Systemtechnik. EMPA, Dübendorf, pp 337-343

3. Hean S, Partl MN (2006) Determination of the decisive factors influencing the behaviour of bridge waterproofing systems with polymer-bitumen membranes. Federal Department of the Environment, Transport, Energy and Communications, Bern, p 597

4. Rosenberg J (2000) Thin pavements with synthetic binder used in Denmark. Asphalt De., Danish Road Institute, Roskilde

5. Hean S, Partl MN (2003) Mastic asphalt and waterproofing components for bridge and tunnel construction. Presented at the proceedings of 12 th int. flexible pavements conference, Melbourne

6. Partl MN (2004) Deterioration mechanisms in polymermodified bitumen's water proofing membrane sheets during torching. Swiss Federal Laboratories for Material Science and Technology, Duebendorf, p 577

7. Architekten-Verein SI (1999) Prüfungen und anwendungsgebite polymerbitumen-dichtungsbahnen-schälzugprüfungen, vol SIA 281/2, SN 564 281/2, ed. Zurich

8. Architekten-Verein SI (1999) Bitumenhahnen-haftzugprüfung, vol SIA 281/3, SN 564 281/3, ed. Zurich

9. Galliot C, Luchsinger RH (2011) Uniaxial and biaxial mechanical properties of ETFE foils. Polym Test 30:356-365

10. Kinloch AJ, Lau CC, Williams JG (1994) The peeling of flexible laminates. Int J Fract 66:45-70

11. Moore DR, Williams JG (2001) Peel testing of flexible laminates. Fract Mech Test Methods Polym Adhes Compos 28:203-223

12. Blackman BRK, Hadvinia H, Kinloch AJ, Williams JG (2003) The use of a cohesive zone model to study the fracture of fiber composites and adhesively-bonded joints. Int J Fract 119:25-46

13. Hadavinia H, Kawashita L, Kinloch AJ, Moore DR, Williams JG (2006) A numerical analysis of the elastic-plastic peel test. Eng Fract Mech 73:2324-2335

14. Hailesilassie BW, Partl MN (2013) Adhesive blister propagation under an orthotropic bituminous waterproofing membrane. Constr Build Mater (accepted manuscript and under review in Elsevier Editorial system)

15. Georgiou I, Hadavinia H, Ivankovic A, Kinloch AJ, Tropsa V, Williams JG (2003) Cohesive zone models and the plastically deforming peel test. J Adhes 79:239-265

16. Williams JG, Hadavinia H (2001) Analytical solutions for cohesive zone models. J Mech Phys Solids 50:809-825

17. Fini EH, Al-Qadi IL (2011) Development of a pressurized blister test for interface characterization of aggregate highly polymerized bituminous materials. J Mater Civ Eng 23:656-663

18. Van Hemelrijck D, Ramault C, Makris A, Clarke A, Williamson C (2007) Biaxial testing of fiber reinforced composites. Presented at the 16th international conference on composite materials, Kyoto

19. Galliot C, Luchsinger RH (2009) A simple model describing the non-linear biaxial tensile behaviour of PVC-coated polyester fabrics for use in the finite element analysis. Compos Struct 90:438-447

20. Reese S, Raible T, Wriggers P (2001) Finite element modeling of orthotropic material behaviour in pneumatic membranes. Int J Solid Struct 38:9525-9544

21. Nase M, Lange B, Grellmann W (2008) Fracture mechanics on polyethylene/polybutene-1 peel films. Polym Test 27:1017-1025

22. Schweizer Norm (1999) Polymerbitumen-Dichtungsbahnen Schälzugprüfungen, vol 281/2, ed. swiss, Schweizerischer Ingenieur- und Architekten-Verein

23. Kim K-S, Aravas N (1988) Elastoplastic analysis of the peel test. Int J Solids Struct 24:417-438

24. Hohlfelder RJ (1999) Bulge and blister testing of the films and their interfaces. Degree of Doctor of Philosophy, Materials Science and Engineering, Stanford University, Stanford 
25. Kai-Tak W, Yiu-Wing M (1995) Fracture mechanics of a new blister test with stable crack growth. Acta Metall Mater 43:4109-4115
26. Robert JH, William DN, Huihong L, Christopher EDC (1999) Blister test analysis methods. Mater Res Soc Symp Proc 356:585-590 